\title{
Aggressiveness Forms of Adolescents in Mono and Polyethnic Classes and Their Relationship with Interpersonal Relationship Types
}

\author{
Angelica Pronina \\ Correponding author, Bunin Yelets State University, Russia, apronina@yahoo.com
}

Evgeniya Gerasimova

Bunin Yelets State University, Russia,nauka@elsu.ru

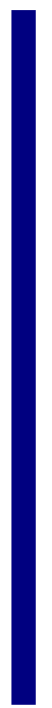

\begin{abstract}
The purpose of our research is to reveal how various forms of aggression affect the types of interpersonal relations between teenagers learning in mono and multi ethnic environment. Aggression was diagnosed with the Buss-Durkee Hostility Inventory (BDHI); the type of interpersonal relations was determined by Timothy Leary's Interpersonal Behavior Circle Personal Inventory (the "Leary" Personality Test). Differences in the forms of aggression showed by teenagers learning in mono and multi ethnic environment were identified with the Student's t-test; relationship between forms of aggression and types of interpersonal relations were identified with the Spearman Rank-Order Correlation (p). The sample involved 236 teenagers between the ages of 13.5-15. The study revealed differences between forms of aggression showed by teenagers learning in mono and multi ethnic environment such as indirect aggression, negativism, guilt and suspicion. Correlation analysis revealed differences in the relationship between forms of aggression such as assault aggression, indirect aggression, guilt and types of interpersonal relationships. It was found that the multiethnic composition of microsociety reduces the manifestation of many forms of aggression among teens, increases the sense of guilt and does not affect any type of interpersonal relationships.
\end{abstract}

Keywords: aggression forms, interpersonal relationship types, mono ethnic environment, multi ethnic environment, age mates

\section{INTRODUCTION}

The current political and social situation in the world is characterized by an increase in ethnic diversity, intensified migration processes (especially uncontrolled ones) and various manifestations of ethnic and national tensions (Mastikova, 2016).

In ethno-cultural social environment, intergroup relations are determined in accordance with the specific features of ethnic diversity (Phalet et al., 2015). In Eastern and Central

Citation: Pronina, A., \& Gerasimova, E. (2018). Aggressiveness Forms of Adolescents in Mono and Polyethnic Classes and Their Relationship with Interpersonal Relationship Types. International Journal of Instruction, 11(4), 1-16. https://doi.org/10.12973/iji.2018.1141a 
Europe (for example, in Slovakia), migrants are subject to various forms of violence (Blazek, 2014). When apply the generalized models of structural equations to 2014 European Social Survey data, it is possible to find that life in more diverse communities is negatively associated with intergroup contact (Laurence et al., 2017). A total of 3178 Arab-Palestinian teenagers (aged 13-18 years) have completed an anonymous poll, which revealed that $28.4 \%$ of respondents had been committing serious assault violence against teens of other ethnic groups at least once a month (Massarwi and KhouryKassabri, 2017). Alarmingly, there is a high level of discrimination among the young people: two-thirds of teens were verbally abused, and one-sixth - assaultly were abused because of their ethnicity last year (Brown et al., 2014).

Two psychological reasons among many reasons that lead to interethnic conflicts can be distinguished (Rakhmatulin, 2013).

The first one is associated with the sense of belonging to a certain ethnos, contrast between own social/ethnic group and the others. The second is known as the "scapegoat", when the repressed negative and antisocial qualities of a personality are projected onto others, usually people of a different nationality. These reasons have a significant impact on the formation of ethnic intolerance and hostility (Rakhmatulin, 2013).

In the framework of a new constructionist paradigm of Russian sociological science, it is able to study the behavior of a person and his/her attitude to other people not only as a particular personality, but also as a representative of a certain social and ethnic group, representative of society and ethnos (Zhade et al., 2016).

Aggression and hostility have both external and internal effect. In the first case, they stipulate the features of interpersonal interaction, in the second - they serve as a psychological defense (Yarmolenko, 2004).

Ethno-political violence, ethnic tensions and national conflicts are caused by various reasons, associated with a number of negative psychological and behavioral outcomes (Light, 2017).

It is possible to consider aggression and hostility in the context of negative attitude towards the representatives of another culture and ethnos. Particular works disclose the issue of fatal out-group hostility as a means of maintaining group identification and stability (Vedder et al., 2016).

Adolescence is the most sensitive period in relation to external influences. Teenagers as a socio-demographic group have a number of socio-psychological characteristics due to their transitional age, unstable mind, biological maturation, the emotional component predominance, categorical judgments, maximalism, advice rejection, penchant for disobeying existing patterns of social development, regulated daily life. Instable world outlook, inadequate socio-psychological maturity, search for one's place in life, risk and social protest make the youth the most vulnerable group to extremist influence (Zinchenko et al., 2016). 
Emotional and sensual self-actualization, as well as the search for entertaining content under the influence of group stereotypes, relations, attitudes and interests, is an important feature of the youth age (Munteanu and Dragomir, 2011). Adolescent crisis is manifested in the form of violent acts and episodes that can be initiated due to the ambiguous status of a teenager (Faris and Ennett, 2012).

Adolescence is characterized by specific features typical for this ontogenetic period: self-defense, jealous and biased attitude toward own personality, which structural component involves national identity (Benish-Weisman, 2016) and status among the age mates (Lee et al., 2017).

In this study, the hypothesis is as follows:

- forms of aggression and types of interpersonal relations between teenagers learning in mono and multi ethnic environment have significant differences;

forms of aggression showed by teenagers learning in mono and multi ethnic environment can be correlated with the type of interpersonal relations.

Research results will make it possible to supplement fundamental and applied research on the problems of teens' ethnic identity effect on the affective (emotional) sphere and the sphere of relationships with teens of another ethnicity. They will also make it possible to develop psycho-pedagogical conditions and programs for addressing the problem of preventing and showing aggression in interpersonal relations between teenagers in multi-community and groups.

\section{Relevant Research}

Research on various aspects of aggression and hostility among teens shows that assault violence against age mates is a general form of aggression while the verbal violence is the most common form of aggression (Potirniche and Rodica, 2014). It also confirms a correlation between self-esteem, extraversion/introversion and aggressive behavior (Paisi-Lazarescu, 2014).

A detailed analysis of studies was conducted in 2005-2015 on the problem of racial/ethnic violence among teens and it revealed the race/ethnicity-based complexities in relationships and interpersonal violence among teens, which are justified by ethnicity significance (Rojas-Gaona et al., 2016).

Experimental results on identifying peculiarities of friendly relations in a group of students of different nationalities have showed that ethnic aspects can have different effects on friendship and negative ties with age mates of different nationalities. In particular, interethnic friendship in a group of students of different nationalities is less probable (Boda and Néray, 2015).

Studies of inter-ethnic violence between schoolchildren in a multi ethnic class have revealed that the choice of a student as an object of bullying and violence is based on his/her nationality; the predominance of inter- and intra-ethnic authoritarianism depends on the level of ethnic diversity in the classroom; inter-ethnic and intra-ethnic bullying increase with increasing levels of ethnic diversity (Tolsma et al., 2013). 
Research on the influence of students' attitudes on the aggressive behavior of teens has showed that aggression is associated with students' status in the group (the higher is the status of the group the greater is the chance to record its members showing aggression) and increases in relation to age mates that do not respond to "leader's" friendship, (Faris and Ennett, 2012). Aggression towards socially preferred students is associated with their greater popularity in the group (Peets and Hodges, 2014).

At the same time, there are foreign studies describing the positive attitude of teens learning in multi ethnic environment, as well as friendship with representatives of other ethnic groups: in multi ethnic schools, interethnic friendship relations are most often of high quality and depend on ethnic diversity (Bagci et al., 2014), friendly relations of the majority of age mates were based on national identity and related with friendly relations with representatives of other ethnic groups (Munniksma et al., 2015). The way the teens percept the positive standards of contact in the class and the cultural distance has predicted the friendship relations between immigrants and non-immigrants (Schachner et al., 2015). Research on parallel and longitudinal relationships between ethnic identity and aggression showed by age mates in groups of immigrated teens show that ethnic identity is negatively linked to aggression and contributes to a relative reduction in future aggression against members of other nationalities (Benish-Weisman, 2016).

Early detection of negativistic manifestations and aggression will allow timely implementing preventive measures, correcting and preventing their further distribution. Our analysis of scientific works shows that there is insufficient number of studies revealing the differences in the forms of aggression showed by teenagers learning in mono and multi ethnic environment, as well as their correlation with the types of interpersonal relations in the class. These issues require experimental study and analysis. Therefore, it is expedient to study the differences in the forms of aggression and hostility showed by teenagers learning in mono and multi ethnic environment, as well as to study whether they influence the type of interpersonal relations among students in the group.

\section{METHOD}

\section{Design}

The study was conducted between January 2017 and May 2017.

We used the following diagram during the experiment. Block $I$ - diagnosing aggression of teenagers' learning in mono and multi ethnic environment. Aggression and hostility were diagnosed with the Buss-Durkee Hostility Inventory (BDHI). This is a 75-item true-false personality inventory. Based on processed and interpreted results, we determined the forms of aggression and the degree of their severity.

Block II - diagnosing interpersonal relations between teenagers' learning in mono and multi ethnic environment. Interpersonal relations were diagnosed with the Timothy Leary's Interpersonal Behavior Circle Personal Inventory ("Leary" Personality Test), which included 128 evaluative judgments grouped into 8 subscales characterizing the following types of interpersonal relationships: authoritarian, selfish, aggressive, 
suspicious, subordinate, dependent, friendly, altruistic. Based on diagnostic results, we determined the severity indices for different types of interpersonal relations.

Block III - comparative analysis of aggression showed by and interpersonal relations between teenagers learning in mono and multi ethnic environment. Differences in aggression and interpersonal relationships were identified with the Student's t-test in SPSS Statistics.

Block $I V$ - finding the relationship between aggression showed by and interpersonal relations between teenagers learning in mono and multi ethnic environment. Since data distribution for each method did not match the normal distribution, relationship between the indices of hostility, aggression and interpersonal relationships was calculated with the Spearman Rank-Order Correlation ( $\mathrm{p}$ ) in the SPSS Statistics.

The diagnosis was carried out in an individual form under the supervision of school psychologist in order to exclude possible copying, rewriting, discussion of answers of other possible, which could be performed during the diagnosis in a group.

Before the procedure, we informed the teens that diagnosis results would be confidential. We asked the subjects to answer sincerely and truthfully, and to write any symbol or sign in the "subject" column of the registration form.

The BDHI of each teenager is a 75-item true-false registration form.

\section{Participants}

The survey was taken by 236 teenagers (7-8 grades) learning at schools of the Lipetsk and Sakhalin Regions: 116 teenagers were learning in mono ethnic environment (Lipetsk Region), and 120 - in multi ethnic environment (Sakhalin Region) (see Table $1)$.

Table 1

Diversification of schoolchildren by nationality in multi ethnic class

\begin{tabular}{ll}
\hline Nationality & Percentage \\
\hline Russian representatives & 33.8 \\
\hline Armenians & 9.7 \\
\hline Azeris & 4.6 \\
\hline Gypsies & 7.6 \\
\hline Tatars & 12.2 \\
\hline Chuvashes & 3.8 \\
\hline Ukrainians & 8.8 \\
\hline Koreans & 3.5 \\
\hline Mordovians & 2.5 \\
\hline Belarusians & 5.5 \\
\hline Nivkhes & 3.8 \\
\hline Ulta people & 3.8 \\
\hline Mari people & 0.4 \\
\hline
\end{tabular}

Participants of the experiment were 13.5-15 years old (mean age: 14.2; standard deviation: \pm 0.4 ). 


\section{Instruments}

In the study each participant was individually examined. There were no risks and inconveniences associated with participation in the study. We analyzed which survey items may be difficult for teens to understand (meaning of words or situation in general). Teenagers took part in the experiment on a voluntary basis, and we received a written agreement from their parents. Each diagnostic method was applied by an experimenter under the supervision of a school psychologist, who monitored the compliance with ethical standards. All information for each subject was coded and entered into the coding table. On the one hand, this provided confidentiality of results and, on the other hand - was used to process data (variables) in SPSS Statistics.

Statistical data analysis was carried out with the IBM SPSS Statistics 22.

We used the Kolmogorov-Smirnov Test, designed to compare the experimental data with normal distribution, in order to reveal normal distribution. The test showed that the attributed distribution in the sample of mono ethic teenagers and in the sample of multi ethic teenagers follows the law of normal distribution and testifies to the legitimacy of applying the Student's t-test.

Data reliability is ensured by the reliability and validity of diagnostic methods, their compliance with the research goals and the age of the test subjects, accurate adherence to the procedure, representative sampling and by the application of statistical data processing methods.

The answers were assessed according to eight scales: assault, indirect aggression, verbal aggression, irritability, negativism, resentment, suspicion and guilt. Results were processed with a processing key - inventory number distributions by scales and scoring the corresponding true-false answers in each scale. Aggression index was calculated for each scale by summing up the scores.

The "Leary" Personality Test was carried out with each teenager individually. He/she was offered a registration form with 128 evaluative judgments. The following instruction was used during the completing: State positive with a + sign for those judgments that correspond to your self-image. If you are not certain that the + sign should be used - write nothing.

These judgments are grouped into 8 factors (octant): each octant corresponds to a certain type of interpersonal relations: authoritarian, independent // dominant, aggressive, distrustful // skeptical, subordinate // dependent, cooperative, altruistic. The scores were calculated with a key for each octant.

\section{FINDINGS}

In Block I, based on the BDHI results, we found that aggression index of the total sample has a moderate degree of severity (Figure 1) 


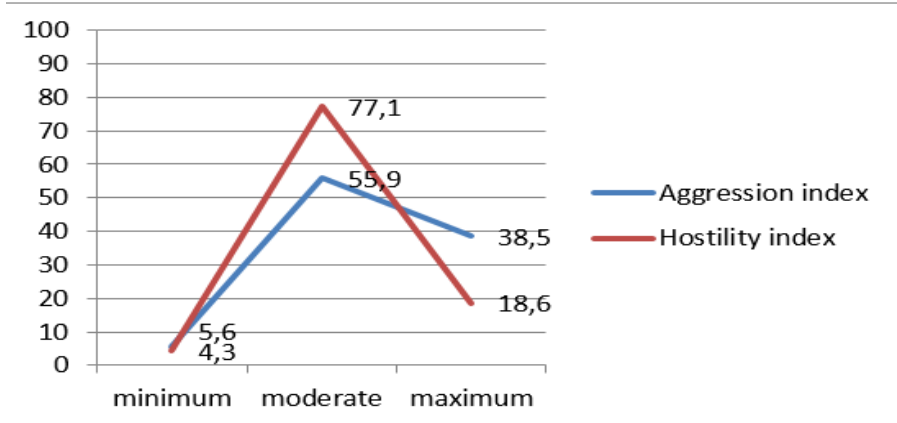

Figure 1

Percentage ratio of aggression severity among teens in the total sample, $\%$

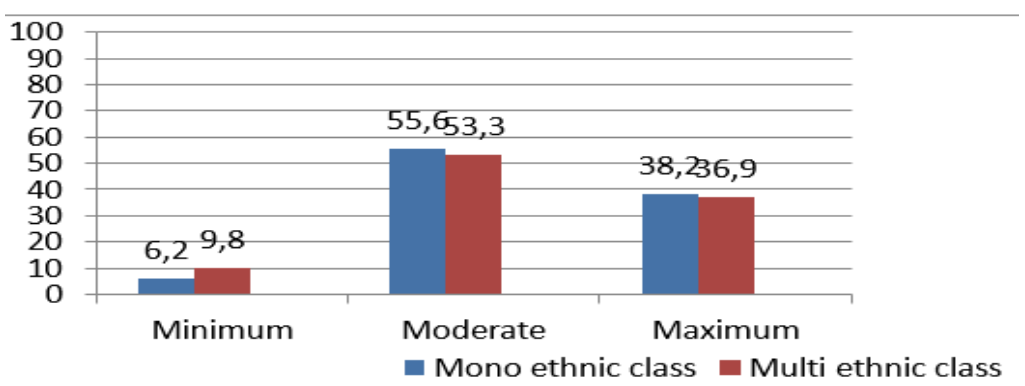

Figure 2

Percentage ratio of aggression severity among teens' learning in mono and multi ethnic environment, \%

At the same time, diagnostic results show that the maximum aggression severity is higher among mono ethnic teenagers compared to multi ethnic teenagers. The minimum aggression severity is higher among the multi ethnic teenagers than the mono ethnic teenagers.

Table 1

Mean values (standard deviation) of severity: different forms of aggression showed by teenagera learning in mono and multi ethnic environment

\begin{tabular}{|c|c|c|c|c|c|c|c|c|}
\hline & \multicolumn{6}{|c|}{ Forms of Aggression } & \multicolumn{2}{|c|}{ Forms of Hostility } \\
\hline & 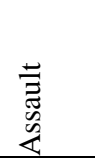 & $\begin{array}{l}\bar{J} \\
\stackrel{0}{0} \\
>\end{array}$ & 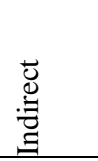 & 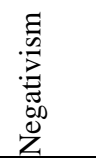 & 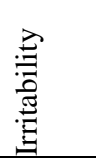 & 奇 & 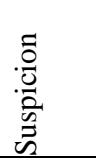 & 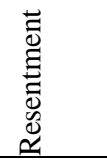 \\
\hline $\begin{array}{l}\text { Mono } \\
\text { class }\end{array}$ & $\begin{array}{l}75.2 \\
(27.4)\end{array}$ & $\begin{array}{l}71.6 \\
(24.6)\end{array}$ & $\begin{array}{l}78.6 \\
(27.1)\end{array}$ & $\begin{array}{l}65.5 \\
(28.9)\end{array}$ & $\begin{array}{l}73.1 \\
(20.9)\end{array}$ & $\begin{array}{l}57.8 \\
(27.4)\end{array}$ & $\begin{array}{l}72.1 \\
(27.4)\end{array}$ & $\begin{array}{l}72.2 \\
(31.5)\end{array}$ \\
\hline Multi ethnic cl & $\begin{array}{l}73.0 \\
(23.5) \\
\end{array}$ & $\begin{array}{l}68.4 \\
(25.9) \\
\end{array}$ & $\begin{array}{l}69.6 \\
(26.2) \\
\end{array}$ & $\begin{array}{l}56.8 \\
(31.7) \\
\end{array}$ & $\begin{array}{l}69.7 \\
(24.1) \\
\end{array}$ & $\begin{array}{l}61.9 \\
(28.3) \\
\end{array}$ & $\begin{array}{l}61.8 \\
(28.2) \\
\end{array}$ & $\begin{array}{l}59.3 \\
(28.0) \\
\end{array}$ \\
\hline
\end{tabular}

International Journal of Instruction, October $2018 \bullet$ Vol.11, No.4 
Calculation of mean values for particular forms of aggression allowed making conclusion about high mean values in mono ethnic environment compared to the multi ethnic environment. We also found that mean values for guilt are higher in teens' learning in multi ethnic environment than in teens' learning in mono ethnic environment.

The highest mean values for indirect and assault aggression were measured in both samples. Mean values for suspicion were almost equally high; mean values for resentment were average in mono ethnic groups. The lowest mean value was measured for guilt in mono ethnic environment. This indicates the low ability of teen learning in these classes to experience feelings of guilt in the process of and after aggression. The lowest mean value for negativism was measured in teens' learning in multi ethnic environment.

In Block II, we identified the varying degrees and indices of interpersonal relations among the subjects.

Table 2

Mean values (standard deviation) and percentage ratio for different types of interpersonal relationships between teenagers learning in mono and multi ethnic environment

\begin{tabular}{|c|c|c|c|c|c|c|c|c|}
\hline & 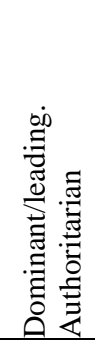 & 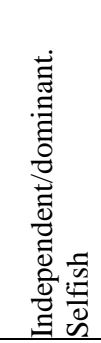 & 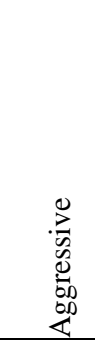 & 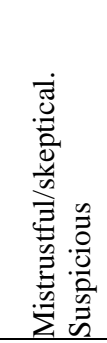 & 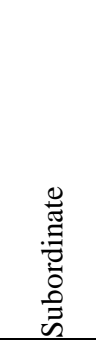 & 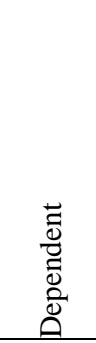 & 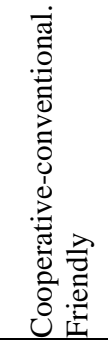 & 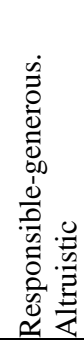 \\
\hline \multicolumn{9}{|c|}{ Mean values (standard deviation) } \\
\hline $\begin{array}{l}\text { Mono } \\
\text { ethnic class }\end{array}$ & $\begin{array}{l}12.6 \\
(2.36) \\
\end{array}$ & $\begin{array}{l}10.8 \\
(2.69) \\
\end{array}$ & $\begin{array}{l}13.1 \\
(2.98) \\
\end{array}$ & $\begin{array}{l}10.9 \\
(2.77) \\
\end{array}$ & $\begin{array}{l}14.2 \\
(3.06)\end{array}$ & $\begin{array}{l}11.6 \\
(3.09)\end{array}$ & $\begin{array}{l}10.5 \\
(2.68)\end{array}$ & $\begin{array}{l}11.6 \\
(2.73) \\
\end{array}$ \\
\hline $\begin{array}{l}\text { Multi } \\
\text { ethnic class }\end{array}$ & $\begin{array}{l}11.6 \\
(2.46) \\
\end{array}$ & $\begin{array}{l}11 \\
(2.65) \\
\end{array}$ & $\begin{array}{l}10.7 \\
(3.66) \\
\end{array}$ & $\begin{array}{l}11.0 \\
(2.72) \\
\end{array}$ & $\begin{array}{l}10.9 \\
(3.78) \\
\end{array}$ & $\begin{array}{l}10.5 \\
(2.71) \\
\end{array}$ & $\begin{array}{l}11.8 \\
(2.25) \\
\end{array}$ & $\begin{array}{l}3.8 \\
(1.80) \\
\end{array}$ \\
\hline \multicolumn{9}{|c|}{ Percentage ratio } \\
\hline $\begin{array}{l}\text { Mono } \\
\text { ethnic class }\end{array}$ & 6.4 & 13.1 & 18.4 & 6.8 & 13.9 & 10.4 & 12.6 & 18.4 \\
\hline $\begin{array}{l}\text { Multi } \\
\text { ethnic class }\end{array}$ & 4.9 & 11.5 & 15.2 & 7.3 & 12.5 & 9.6 & 14.7 & 24.3 \\
\hline
\end{tabular}

Data obtained with the "Leary" Personality Test suggest that mean values in the mono ethnic class are higher among teens with authoritarian, aggressive, subordinate and dependent types of interpersonal relationships. In multi ethnic environment, mean values are higher among teens with selfish, suspicious, friendly and altruistic types of interpersonal relationships.

In the quantitative (percentage) ratio, higher percentages were found in multi ethnic environment among teens with such types of interpersonal relations as friendly, 
altruistic, suspicious, and in mono ethnic environment - among teens with such types of interpersonal relations as authoritarian, selfish, aggressive, subordinate and dependent.

At the same time, mathematical analysis with the Student's t-test allows us to testify to the absence of significant differences in the types of interpersonal relationships among teens' learning in mono and multi ethnic environment.

Table 3

Students' t-tests: comparison of different types of interpersonal relationships between teenagers learning in mono and multi ethnic environment

\begin{tabular}{|c|c|c|c|c|c|c|c|c|}
\hline & 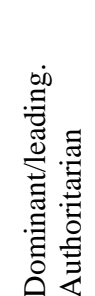 & 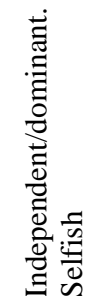 & 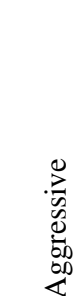 & 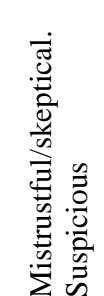 & 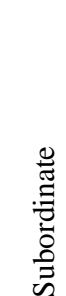 & 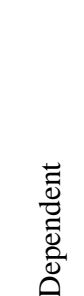 & 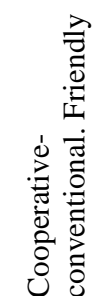 & 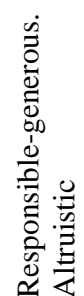 \\
\hline \multicolumn{9}{|c|}{ Significance of differences } \\
\hline $\begin{array}{l}\text { Mono ethnic } \\
\text { class }(n=116)\end{array}$ & 0.001 & 0.55 & 1.75 & 0.79 & 0.51 & 0.003 & 1.67 & 1.24 \\
\hline $\begin{array}{l}\text { Multi ethnic } \\
\text { class }(n=120)\end{array}$ & & & & & & & & \\
\hline
\end{tabular}

Let's present the data of a comparative analysis of aggression and interpersonal relations between teens' learning in mono and multi ethnic environment conducted using the Student's t-test.

Table 4

Students' t-test: comparison of different forms and scales of aggression showed by teens' learning in mono and multi ethnic environment

\begin{tabular}{|c|c|c|c|}
\hline \multirow[b]{2}{*}{$\begin{array}{l}\text { Forms of Aggression and } \\
\text { Hostility }\end{array}$} & \multicolumn{2}{|c|}{ Mean values (standard deviation) } & \multirow[b]{2}{*}{$\begin{array}{l}\text { Significance of } \\
\text { differences }\end{array}$} \\
\hline & $\begin{array}{l}\text { Mono ethnic class } \\
(\mathrm{n}=116)\end{array}$ & $\begin{array}{l}\text { Multi ethnic class } \\
(\mathrm{n}=120)\end{array}$ & \\
\hline Assault & $75.2(27.4)$ & $73.0(23.5)$ & 1.81 \\
\hline Verbal & $71.6(24.6)$ & $68.4(25.9)$ & 1.32 \\
\hline Indirect & $78.6(27.1)$ & $69.6(26.2)$ & $2.43 *$ \\
\hline Negativism & $65.5(28.9)$ & $56.8(31.7)$ & $2.01 *$ \\
\hline Irritability & $73.1(20.9)$ & $69.7(24.1)$ & 1.12 \\
\hline Guilt & $57.8(27.4)$ & $61.9(28.3)$ & $2.44 *$ \\
\hline Suspicion & $72.1(27.4)$ & $61.8(28.2)$ & $2.02 *$ \\
\hline Resentment & $72.2(31.5)$ & $59.3(28.0)$ & 1.115 \\
\hline
\end{tabular}

Note: $*$ - significant differences found at $p<0,05$, T-test $=1.969 ; 2.601$

Analysis showed that differences in aggression among teens' learning in mono and multi ethnic environment were found in the following scales: indirect aggression (2.43), negativism (2.01), guilt (2.44) and suspicion (2.02); and no differences in assault and verbal aggression, irritability and resentment. 
Relationship between aggression showed by and interpersonal relations between teens' learning in mono and multi ethnic environment was determined with the Spearman Rank-Order Correlation (p). This allowed us to create a matrix of mutual correlations and to determine the different types of interrelations.

Table 5

Matrix of mutual correlations between different forms of aggression/hostility showed by and different types of interpersonal relationships between teenagers (mono ethnic class - top line; multi ethnic class - bottom line)

\begin{tabular}{|c|c|c|c|c|c|c|c|c|}
\hline $\begin{array}{l}\text { Forms of Aggression } \\
\text { and Hostility }\end{array}$ & 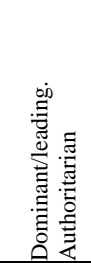 & 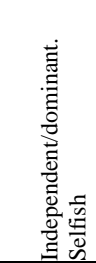 & 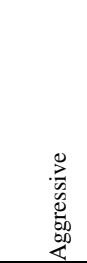 & 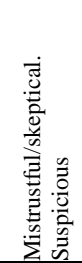 & 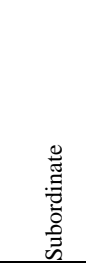 & 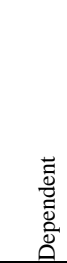 & 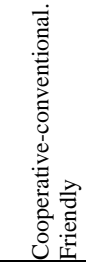 & 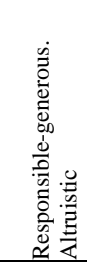 \\
\hline Assault & $\begin{array}{l}0.25^{* * *} \\
-\end{array}$ & $\begin{array}{l}0.26^{* *} \\
0.26^{* *}\end{array}$ & - & - & $\begin{array}{l}-0,184^{*} \\
-\end{array}$ & - & $\begin{array}{l}-0.24 * * \\
-\end{array}$ & $\begin{array}{l}-0.29^{* *} \\
-\end{array}$ \\
\hline Verbal & _ & _- & - & _ & _- & _ & _ & _ \\
\hline Indirect & $\begin{array}{l}-0.26^{* *} \\
-\end{array}$ & $\begin{array}{l}0.35^{* *} \\
-\end{array}$ & - & $\begin{array}{l}0.29^{* *} \\
0.26^{*}\end{array}$ & $\begin{array}{l}0.184 * \\
-\end{array}$ & $\begin{array}{l}0.25^{*} \\
-\end{array}$ & - & - \\
\hline Negativism & & & & & _ & 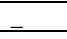 & - & - \\
\hline Irritability & - & $\begin{array}{l}0.184^{*} \\
-\end{array}$ & - & - & - & - & - & - \\
\hline Guilt & $\begin{array}{l}- \\
-0.24^{* *}\end{array}$ & - & - & $\begin{array}{l}0.29^{* *} \\
-\end{array}$ & $\begin{array}{l}- \\
0.184^{*}\end{array}$ & - & $\begin{array}{l}- \\
0.28 * *\end{array}$ & $\begin{array}{l}- \\
0.179^{*}\end{array}$ \\
\hline Suspicion & - & $\begin{array}{l}0.184^{*} \\
-\end{array}$ & $\begin{array}{l}0.184^{*} \\
0.26^{* *}\end{array}$ & - & - & - & - & - \\
\hline Resentment & - & - & - & - & - & - & _- & - \\
\hline
\end{tabular}

Note: $*^{*}-p<0,01 ;^{*}-p<0,05$.

Results of cross correlations between forms of aggression showed by and types of interpersonal relations among teens' learning in mono and multi ethnic environment show some similarities and differences in their structure (Table 5).

In particular, there are no interrelations between verbal aggression, negativism, resentment and all types of interpersonal relations; between suspicion, irritability, indirect aggression and friendly, altruistic types of interpersonal relations; between assault, indirect aggression, irritability, guilt and aggressive type of interpersonal relations; between all indicators of aggression/hostility and dependent type of interpersonal relations in the two studied samples.

At the same time, similarities in the structure of relationship between forms of aggression/hostility and types of interpersonal relations among teens' learning in mono and multi ethnic environment can be traced as follows: between assault aggression and selfish type of interpersonal relations; between indirect aggression and suspicious type 
of interpersonal relations; between suspicion and aggressive type of interpersonal relations. We found the following differences: there is a relationship between assault aggression and authoritarian, subordinate, friendly, altruistic types of interpersonal relations; between indirect aggression and authoritarian, selfish, subordinate, dependent types of interpersonal relations; between suspicion and selfish, aggressive types of interpersonal relations in teens' learning in mono ethnic environment. Naturally, there is no such link in multi ethnic samples. In fact, there is a greater number of relationships between guilt and authoritarian, subordinate, friendly and altruistic types of interpersonal relations in contrast to mono ethnic sample.

The revealed interrelations involve negative reverse relations between assault aggression and the subordinate type of interpersonal relations $(-0.184$, at $\mathrm{p}<0.05)$, between indirect aggression and authoritarian type of interpersonal relations in mono ethnic environment; between guilt and authoritarian type of interpersonal relations $(-0.24$, for $\mathrm{p}<0.05)$ in multi ethnic environment.

Obtained data allowed us to conclude that our hypothesis was partly confirmed.

It is shown that teenagers learning in mono ethnic environment have higher (in percentages) index of aggression/hostility than teenagers learning in multi ethnic environment despite of the overall moderate severity in the total sample. We also measured higher mean values for almost all forms of aggression (assault, verbal, indirect, negativism, irritability, suspicion and resentment), except for guilt, which was somewhat higher in teens' learning in multi ethnic environment.

At the same time, there are insignificant differences in such forms of aggression/hostility among teenagers learning in mono and multi ethnic environment as indirect aggression, negativism, guilt and suspicion. There are also no differences in values measured for assault and verbal aggression, irritability, and resentment. We assume that in ethnically homogeneous and ethnically diverse groups (classes) of adolescents, many forms of aggression have common social and psychological characteristics. It is possible to suggest that inter-ethnic relations of teens in the group reduce manifestations of indirect aggression, negativism and suspicion.

In mono and multi ethnic environment, picture of interpersonal relationships between students looks diverse. In mono ethnic environment, however, aggressive and altruistic types of relations predominate in an equal percentage; the altruistic type prevails among teenagers learning in multi ethnic environment. However, there was no difference between the types of interpersonal relations between teens in these classes, which can be explained by the fact that interpersonal relations in the class are not conditioned by diversity/homogeneity of the ethnic composition.

Correlation analysis in both samples of teenagers learning in mono and multi ethnic environment revealed an insignificant number of moderate correlations between forms of aggression and types of interpersonal relationships.

We found a positive relationship between the assault and many types of interpersonal relationships. This shows that interpersonal relations in an ethnically homogeneous 
group are accompanied by assault and indirect aggression. In particular, authoritarian type of interpersonal relationships is typical for teens, who can use external physical influences on age mates to maintain authority in the group. This confirms the results of studies, in which authoritarian power is accompanied by forceful influences on other people. High-level physical aggression is not typical for friendly and altruistic types of interpersonal relations between teens' learning in mono ethnic groups; low-level physical aggression is typical for a subordinate type of interpersonal relations.

Teens learning in mono and multi ethnic environment have prosperity for selfishness in interpersonal relations, which is accompanied and characterized by high-level physical aggression. Similarity in the presence of such a connection is due to the existence of egoism as an age-specific feature of adolescence.

We found similarities in correlation interrelations between indirect aggression and suspicious type of interpersonal relations. In particular, the higher are the level of distrust, difficulties in communication and fear of a bad attitude, the higher will be the latent aggression.

An aggressive type of interpersonal relations, unfriendly behavior and quick temper increase suspicion as an indicator of hostility.

\section{DISCUSSION}

This research shows that assault as a form of aggression is typical for teenagers learning in mono and multi ethnic environment, which is confirmed by the results presented in (Potirniche and Rodica, 2014). The lack of interrelations between assault and types of interpersonal relations in multi ethnic groups is attributed to the fact that teens learning in groups with a diverse ethnic composition do not use physical and indirect aggression to establish and maintain interpersonal relationships and own status. This is consistent with data on the presence of positive friendly relationships in interethnic groups (Bagci et al., 2014). The level of physical aggression detected in mono and multi ethnic groups was lower than it was noted in other foreign studies (Tolsma et al., 2013). This confirms the data on the low level of aggression provided by Jennifer M. Reingle Gonzalez and Mildred M. Maldonado-Molina (Reingle et al., 2012).

The existence of a relationship between the authoritarian type of interpersonal relations and assault among teens learning in multi ethnic environment confirms the revealed positive relationship between self-efficacy and physical aggression (Piko and Pinczés, 2014). The revealed relationship between the selfish type of interpersonal relationships and aggression in mono ethnic groups is confirmed by the study illustrating that teenagers showing signs of narcissism also show more aggression (Barry et al., 2017). Teenagers with a high level of narcissism can try to strengthen their social status through prosocial behavior and aggression (Kauten and Barry, 2014).

In terms of in interpersonal relationships, they have propensity mostly for a sense of guilt; it determines and significantly correlates with almost all types of interpersonal relationships, especially with friendly relations. In particular, we identified a negative interrelation between the guilt and the authoritarian type of interpersonal relationships. 
In other words, the authoritarian type of interpersonal relationships is less strong as the sense of guilt increases among teens learning in a multi ethnic environment. This confirms the existence of a positive interrelation between guilt and friendly, and altruistic types of interpersonal relationships. There is no such an interrelation in mono ethnic environment. The revealed feature is described by T. Colasante, A. Zuffianò, TMalti (2015), who found that a high level of guilt reduces aggression and promotes a positive attitude towards other people.

The absence of interrelations between indirect aggression and types of interpersonal relations indicate greater openness in the relationship between teenagers of different nationalities learning in multi ethnic environment rather in mono ethnic one.

A variety of education programs are developed for teenagers and school teachers to reduce aggression among teenagers learning in multi ethnic environment. Schools should focus on preventive education and counseling teenagers on the problems of relationship with age mates and aggressive behavior. Besides, training teachers and consultants on the job to make them understand these relationships can help teens to improve their relationships with age mates better while reducing aggressive behavior (Kim and Rai Nho, 2017). Measures to develop inter-ethnic friendly relations between immigrants and non-immigrants should be focused on reducing the cultural distance and improving the communication standards within the intergroup (Schachner et al., 2015). As for ethnic discrimination, we suggest promoting positive cultural exchanges between students of different ethnic groups, such as participation in ethnic events or other forms of active cultural preservation (Brown et al., 2014). We developed measures to reduce discrepancies and differences between ethnic groups, ways to enhance the opportunities for positive social interaction between representatives of ethnic majority and minorities and inter-group friendly relations (Vervoort et al., 2010).

It is important to note that this study was not without limitations. Firstly, strict correlation analysis did not allow identifying differences between different forms of aggression showed by teenagers of specific ethnic groups. Secondly, it did not allow establishing the cause-and-effect relations between the ethnic identity and forms of aggression. Thirdly, it is necessary to check whether our conclusions can really be generalized for other groups and ages. Our study can be extended and continued in a direction of gender differences between different forms of aggression, showed by teenagers learning on mono and multi ethnic environment, and their correlation with different types of interpersonal relationships.

\section{CONCLUSION}

This study reveals differences between different forms of aggression, showed by teenagers learning in mono and multi ethnic environment, and their correlation with different types of interpersonal relationships. The results show that there are some differences in the forms of aggression, in particular indirect aggression, negativism, guilt and suspicion, as well as that there are no differences between different types of interpersonal relationships between teens learning in mono and multi ethnic environment. Correlation analysis of different forms of aggression and types of 
interpersonal relationships showed that there are no interrelations between verbal aggression, negativism, resentment and all types of interpersonal relationships. The closest relationship is between the assault, indirect aggression and various types of interpersonal relationships, as evidenced by many previous studies (for example, Nedelusa Potirniche). Teenagers learning in multi ethnic environment have the closest correlation between guilt and various types of interpersonal relationships, as evidenced in previous studies (for example, T. Colasante, A. Zuffianò, TMalti).

This study describes the emotional and affective aspects of adolescents, their interpersonal and interethnic relationships in the group. Thus, we found that there are differences in the level of aggression showed by teens learning in mono and multi ethnic environment. These differences may affect interpersonal relationships. Thus, we have to study these aspects carefully in order to reduce the level of aggression/hostility. We have to continue shaping the tolerant attitude of teenagers to representatives of other nationalities and ethnicity. This, in turn, will prevent various manifestations of xenophobia and youth extremism.

\section{ACKNOWLEDGEMENTS}

The research was carried out within the framework of the State Order issued by the Ministry of Education and Science of the Russian Federation (Project No. 27.9480.2017/NM Project development for regional models of ethno-cultural education, which includes the content of general and pre-school education focused on shaping ethnic and civil identity among students, teaching interethnic tolerance and patriotism).

\section{REFERENCES}

Smith, P. K., Blumberg, H., Rutland, A. (2014). Cross-ethnic friendships: Are they really rare? Evidence from secondary schools around London. International Journal of Intercultural Relations, 41, 125-137.

Barry, Ch. T., Katrina, H.M, Dougall, A.C.б Andersonб A.L. (2017). Global and contingent self-esteem as moderators in the relations between adolescent narcissism, callous-unemotional traits, and aggression. Personality and Individual Differences, 123, 1-5.

Benish-Weisman, M. (2016). Brief report: Ethnic identity and aggression in adolescence: A longitudinal perspective. Journal of Adolescence, 47, 131-134.

Blazek, M. (2014). Migration, vulnerability and the complexity of violence: Experiences of documented non-EU migrants in Slovakia. Geoforum, 56, 101-112

Boda, Z., Néray, B. (2015). Inter-ethnic friendship and negative ties in secondary school. Social Networks, 3, 57-72.

Brown, C., Langille, D., Tanner, J., Asbridge, M. (2014). Health- Compromising Behaviors Among a Multi-Ethnic Sample of Canadian High School Students: RiskEnhancing Effects of Discrimination and Acculturation. Journal of Ethnicity in Substance Abuse, 13(2), 158-178. 
Bushman, B.J., O'Brien, E.H. (2012). Aggression. Encyclopedia of Human Behavior (Second Edition), pp. 37-43.

Colasante, T., Zuffianò, A., Malti T. (2015). Do moral emotions buffer the angeraggression link in children and adolescents? Journal of Applied Developmental Psychology, 41, 1-7.

Faris, R., Ennett, S. (2012). Adolescent aggression: The role of peer group status motives, peer aggression, and group characteristics. Social Networks, 34I(4), 371-378.

Kauten, R., Barry, Ch. T. (2014). Do you think I'm as kind as I do? The relation of adolescent narcissism with self- and peer-perceptions of prosocial and aggressive behavior. Personality and Individual Differences, 61-62, 69-73.

Kim, S., Rai Nho, C. (2017). Longitudinal reciprocal effects between peer relationship difficulties and aggressive behaviors in Korean adolescents. Children and Youth Services Review.

Laurence, J., Lee, B. (2017). Countervailing contact: Community ethnic diversity, antiimmigrant attitudes and mediating pathways of positive and negative inter-ethnic contact in European societies. Social Science Research.

Lee, S., Foote, J., Wittrock, Z., Xu, S., Li, N., French, D.C. (2017). Adolescents' perception of peer groups: Psychological, behavioral, and relational determinants. Social Science Research, 65, 181-194.

Light, M.T. (2017). Re-examining the relationship between Latino immigration and racial/ethnic violence. Social Science Research, 65, 222-239.

Massarwi, A.Ah., Khoury-Kassabri, M. (2017). Serious assault violence among ArabPalestinian adolescents: The role of exposure to neighborhood violence, perceived ethnic discrimination, normative beliefs, and, parental communication. Child Abuse \& Neglect, 63, 233-244.

Mastikova, N.S. (2016). Ethnic tensions in Russia and Europe (according to the European Social Survey, 2012). Sociological Journal, 22(1), 95-113.

Munniksma, A., Verkuyten, M., Flache A., Stark T., Veenstra, R. (2015). Friendships and outgroup attitudes among ethnic minority youth: The mediating role of ethnic and host society identification. International Journal of Intercultural Relations, 44, 88-99.

Munteanu, A.D., Dragomir, G.-M. (2011). Configuration of gender aggressiveness with teenagers. Procedia - Social and Behavioral Sciences, 30, 63 - 67.

Paisi-Lazarescu, M. (2014). Psychological Variables of Aggression at Teenagers. Procedia - Social and Behavioral Sciences, 127, 743-747.

Peets, K., Hodges, E.V.E. (2014). Is popularity associated with aggression toward socially preferred or marginalized targets? Journal of Experimental Child Psychology, $124,112-123$. 
Phalet, K., Baysu, G., Van Acker, K. (2015). Ethnicity and Migration in Europe. International Encyclopedia of the Social \& Behavioral Sciences (Second Edition), pp. $142-147$.

Piko, B.F., Pinczés, T. (2014). Impulsivity, depression and aggression among adolescents. Personality and Individual Differences, 69, 33-37.

Potirniche, N., Rodica, G. (2014). EnacheSocial Perception of Aggression by High School Students. Procedia - Social and Behavioral Sciences, 127, 464-468.

Rakhmatulin, R.Yu. (2013). Two Psychological Causes of Ethnic Hostility. European Social Scenario Journal, 11-1(38), 271-275.

Reingle, J.M., Maldonado-Molina, M.M., Jennings, W.G., Komro, K.A. (2012). Ethnic Differences in Trajectories of Aggression in a Longitudinal Sample of High-Risk, Urban Youth. Journal of Adolescent Health, 51(1), 45-52.

Rojas-Gaona, C., Hong, J., Peguero, A. (2016). The significance of race/ethnicity in adolescent violence: A decade of review, 2005-2015. Journal of Criminal Justice,46, 137-147.

Russia in figures. (2016). Brief Statistical Book. Rosstat. Moscow, pp. 543. [Electronic resource]. Assess mode: http://www.gks.ru/free_doc/doc_2016/rusfig/rus16.pdf

Schachner, M. K., Brenick, A., Noack, P., van de Vijver, F.J.R., Heizmann, B. (2015). Structural and normative conditions for interethnic friendships in multiethnic classrooms. International Journal of Intercultural Relations, 47, 1-12.

Tolsma, J., van Deurzen, I., Stark, T.H., Veenstra, R. (2013). Who is bullying whom in ethnically diverse primary schools? Exploring links between bullying, ethnicity, and ethnic diversity in Dutch primary schools. Social Networks, 35(1), 51-61.

Vedder, P., Wenink, E., Geel, M. (2016). Explaining negative outgroup attitudes between native Dutch and Muslim youth in The Netherlands using the Integrated Threat Theory. International Journal of Intercultural Relations, 53, 54-64.

Vervoort, M.H. M., Scholte, R. H. J., Overbeek, G. (2010). Bullying and Victimization Among Adolescents: The Role of Ethnicity and Ethnic Composition of School Class. $J$ Youth Adolescence, 39, 1-11.

Zhade, Z.A., Shadzhe, A.Y., Lyausheva, S.A. (2016). The state of ethno-social processes and the level of ethnic tension in the south of Russia: expert opinion. Theory and Practice of Social Development. Sociological Sciences, 5, 18-23.

Zinchenko, Y.P., Perelygina, E.B., Zotova, O.Y. (2016). Perceptions of Extremism in the Youth Daily Consciousness. Procedia - Social and Behavioral Sciences, 233, 322 326.

Yarmolenko, G.P. (2004). Aggression and hostility in interpersonal interaction (student youth case study): extended abstract of PhD in Psychology. St. Petersburg. 